\title{
An Ab Initio Solution Of Interdependence: Social Organization With First Principles
}

\author{
W.F. Lawless ${ }^{\mathrm{a}}$, Stan Rifkin ${ }^{\mathrm{b}}$, and D.A. Sofge ${ }^{\mathrm{c}}$ \\ ${ }^{a}$ Paine College, 1235 15th Street, Augusta, GA, USA \\ ${ }^{b}$ US Air Force Office of Scientific Research, 875 N. Randolph St., Arlington, VA, USA ${ }^{1}$ \\ ${ }^{c}$ Naval Research Laboratory, 4555 Overlook Avenue SW, Washington, DC, USA
}

\begin{abstract}
A special issue of Science, the National Academy of Sciences, the military, and economists have called for a new theory of interdependence, $\iota$. Constructed around the notion of bistable social reality (i.e., complementarity between conjugate or Fourier pairs), we have developed a social physics of $\iota$ for organizations and systems of humans, machines and robots that has shown some validity. But because of the loss of meaning associated with understanding $\iota$ states or interactions between social Fourier pairs, we consider it high-risk research.
\end{abstract}

Keywords: interdependence; social theory; conservation of information; Nash equilibria.

PACS: 02.50.Le, 03.67.-a

\section{THEORY}

Collecting information from individuals in organizations for social network analysis (SNA) is common (e.g., surveys, interviews, observations). However, even when the information is readily available, the signals collected from social networks have not led to valid predictions [1]. But for "dark" social networks, comprised of illicit drug gangs or terrorists [2], uncovering information for an SNA is orders of magnitude more difficult. This failure has led to a wide request for new theory to better understand the effects of interdependence, $\iota$, in social networks and organizations [3]. For example, Barabási [4] concluded that new theory is needed "to understand the behavior of the systems ... [to] form the foundation of a theory of complexity" (p. 413).

Methodological individualism (MI) [5] unifies traditional social and game theories. MI has been used for decades. Game theory was one of the first to model $\iota$ rationally and solve it in the laboratory for two sets of non-cooperative opponents. These "toy" problem solutions are known as Nash equilibria, which Luce and Raiffa [6] believed resulted in unfair distributions of a game's resources among participants. Axlerod [7] concluded that the unfair distributions from "the pursuit of self-interest" (p. 7) could be controlled with punishment sufficient to promote the evolution of cooperation. But Luce and Raiffa [6] warned that it was unlikely that "any sociology be derived from the single assumption of individual rationality" (p. 196). Outside of the laboratory,

\footnotetext{
${ }^{1}$ The US government retains unlimited rights to reproduce and distribute this article. The views expressed by Stan Rifkin and D.A. Sofge are theirs and do not necessarily represent the views of the US Department of Defense nor its Components.
} 
game theory has not been validated [8] nor has it produced satisfactory solutions [9]. One problem with Nash equilibria is that they largely overlook social effects.

Another problem with MI is that the social learning methods used to justify cooperation require minimal cognition. Punishment and rewards can be applied to mimic the behaviors of any organism, and are simple enough to be used with agentbased models. But neither punishment nor rewards require human intelligence to be effective [10]; this is likely why computational agent systems have not been validated [11][12]. For example, Floreano and Keller [13] define cooperation for evolving robots as "an act increasing both the direct fitness of the individual giving help and the fitness of the individual receiving help" (p. 5), but the fitness of their robots plateau inexplicably possibly because, as we have found [14], social fitness is related to the production of information from competition.

To make ABMs more efficient, we have devised a fundamental theory of social reality based on first principles to model social decision-making [15]. To overcome many of the limitations in classical theories, our new theory for organizations of humans, machines, and artificial agents is built around the common solutions that humans produce daily. To model this solution process, our social physics uses Nash equilibria ${ }^{2}$. We argue that, not only at the quantum level but also for $\iota$, at any one point in time, measurement can do no better than produce classical interpretations of social reality [18]. Because interpretations are based mostly on experience and less on sensory data [19], bistable illusions abound. Bistability implies that multiple interpretations are common and at the root of different cultures, social conflicts, and scientific disagreements (e.g., arguments for and against the Copenhagen interpretation of quantum theory by Bohr and Einstein, respectively; e.g. [20]). Nash equilibria are the mechanisms that a free society uses to reduce uncertainty in solving its social problems, entertain audiences, and legislate its laws, always exhibited as tension between tradeoffs among solutions and phase transitions among deciders.

As an example of tradeoffs in business, Google plans a new business to offer ultrafast web service by installing new fiber-optic lines in selected US cities ${ }^{3}$. Its new model attacks the telecom firms that have invested $\$ 161$ billion in internet lines over the past 13 years, the same firms that Google uses to sell its Android software-based cell phones. But Google needs the Telecoms to improve its support (e.g., for google.docs). The tradeoff: Google has limited experience in operating a physical system of this size and risks embarrassment if it cannot deliver.

In our social physics, this NE of Google and Telecoms represents a valuable asset to society [21] by driving public attention back and forth between bistable interpretations across time, generating a social-psychological harmonic oscillator (SPHO). Based on findings from the literature regarding our view of bistable reality, SPHO (competition) situations improve learning [22], political processes [23], decision-making in the courtroom [24] and environmental cleanup [25]. An SPHO

\footnotetext{
${ }^{2}$ A Nash equilibrium (NE) is commonly a stable solution that participants cannot improve based on choices by others; e.g., when two market firms compete directly, "aggressive moves ... trigger ruinous price wars" [16]. We reinterpret NE as a set of opposed positions defended by self-interests. Those who occupy NE drive their relatively stable views into stable opposition with the goal of obtaining widespread social, financial, or political support for their self-interests. From our perspective, with reality being not easy to access or capture ([17], p. 202), an NE plus feedback provide sufficient information to computationally solve ill-posed problems [15].

${ }^{3}$ Wall Street Journal (2/11/10) "Google jolts telecom rivals," retrieved 2/11/10 from wsj.com.
} 
best disambiguates solution paths for robots [26]. In contrast, the absence of an SPHO indicates minority rule such as a dictatorship [27], which significantly reduces social welfare [28]. But SPHOs generate fluctuations that produce information characteristic of a system's stability response that is modeled as the conservation of information (COI).

\section{CONSERVATION OF INFORMATION (COI): A SOLUTION}

A Gaussian distribution coupled to its Fourier transform is a multiplicative Fourier pair that ideally produces a constant for COI. We have identified four mathematically interchangeable sets of Fourier pairs that describe $\iota$ in organizations or systems. First, larger organizations or systems of agents are more stable (lower stock market volatility) or "darker" than smaller ones, a motivation for mergers like the European Union (EU) [21]; however, size is a tradeoff for flexibility. Second, even for wellknown organizations, the more skilled they become, the "darker" should become their internal signals to observers and to themselves [29]; this aspect of our theory rejects Simon's [30] bounded rationality ${ }^{4}$. Third, as certainty in one factor grows, uncertainty in its Fourier cofactor grows, creating orthogonal variables. Illustrating this point for self-reports, the meta-analysis by Baumeister and his colleagues [32] found that selfesteem, arguably the most studied phenomena in psychology, was negligibly correlated to academic and work performance; similarly negligible associations were reported between manager assessments and firm performance [33], between preferences and choices made in games [34], and between the education of US Air Force combat fighter pilots and actual performance [29]. Fourth, and less well-studied, our mathematics predict that the more focused an organization's operational center-ofgravity, the more likely it replicates its business plan geospatially [15]; inversely, fragmentation among US military Medical Department Research Centers significantly impaired their publication rate of research [14], and the oscillations between US Nuclear Regulatory Commission and US Department of Energy reflected an inability to jointly agree on criteria for closing DOE's high-level radioactive waste tanks at the Savannah River Site [35].

By studying organizational fluctuations across these four pairs of interdependent cofactors whether for humans, machines, or artificial agents, COI suggests that it is possible to control a wide array of systems from the information produced in response to perturbations ${ }^{5}$. To complete our theory, we measure social welfare from a social perspective with Lotka-Volterra type equations to produce 3-D limit cycles [36].

We present a brief overview to illustrate how we see the theory coming together in our work-in-progress based on common evidence.

\footnotetext{
${ }^{4}$ Simon's [30] "talking out loud" protocol assumes that experts have full access to their expertise, that this expertise can be articulated to scientist observers, and that the information so derived is valid; but Tversky found that justifications of behaviors and actual behaviors were unrelated; in Shafir \& LeBoeuf [31]; also, Ahdieh [5]. Unlike air-combat maneuvering [29], bounded rationality may operate for expertise in non- $\iota$ situations.

${ }^{5}$ E.g., Wall Street Journal (2010, February 20), "Greece to test markets, EU with offering of new bonds", p. C3: To determine whether bond markets stabilize or to bailout Greece, the launch of a new bond by Greece should act as a market referendum on the EU's political response to its crisis, "Bringing a [bond] deal will crystallize ... high-stakes," said J. Reid, a Deutsch Bank AG credit strategist, London.
} 
Combining Bohr and Adelson suggests that multiple interpretations are arbitrary (e.g., religious and political beliefs) ${ }^{6}$, where the success of an interpretation determines its power? ${ }^{7}$ In turn, system control is determined by numbers of supporters, $N$; when people or organisms are free to self-organize, $N$ determines power by a bottom-up process (e.g., iPod's control of the music market ${ }^{8}$; A Republican replaced a Democrat for US Senator in Massachusetts ${ }^{9}$; and fragmentation from reduced membership has reduced the Anglican Church's power ${ }^{10}$ ). When self-organization is suppressed, $N$ is a top-down process controlled by elites (e.g., the control of institutions by Communists in China ${ }^{11}$; the control of businesses by the Partido Comunista de $\mathrm{Cuba}^{12}$; and the control of political nominations by theocrats in $\operatorname{Iran}^{13}$ ). With $N$ comes control and power.

In self-organized societies, power is controlled by the production and free flow of information, generated by natural and forced perturbations, making it elusive and promoting instability, but stabilizing social and political movements ${ }^{14}$. In suppressed societies, power is governed by control of information, making its manipulation central to a command economy and society ${ }^{15}$.

An example of both of these effects is shown in mergers among businesses and States. Mergers are an attempt to control a market by increasing efficiency. As an example among States, in responding to Greece's indebtedness, the EU bailout is a tradeoff between trying to avoid an increase in "moral hazard" by bailing out a spendthrift government and getting an indebted nation to be fiscally prudent ${ }^{16}$. The tension in the tradeoff is reflected in the wild gyrations in the exchange value of the euro by market investors who think the EU's solution for Greece is inadequate and Greek citizens who reject their loss of sovereignty.

\footnotetext{
${ }^{6}$ Power, per Foucault [37], is embedded in a society's constructs of reality and knowledge as measured by how it or its agents discipline its members.

${ }^{7}$ For example, the American Psychiatric Association's Diagnostic and Statistical Manual's forthcoming version V sets the criteria for mental disorders based on empirical epidemiology, but it has been criticized for being more political than scientific [38].

$\mathrm{DSM} \neg \mathrm{V}$ is expected to raise the rate of mental illness by not drawing clear boundaries between disorders [39].

${ }^{8} \mathrm{iPod}$ market share at 73.8\%; retrieved 2/11/10 from www.afterdawn.com/news/archive/19294.cfm

${ }^{9}$ From CNN (1/19/10) "Brown wins Massachusetts Senate race", retrieved 2/11/10 from www.cnn.com.

${ }^{10}$ USAToday (2009, June 21), "U.S. Anglican Church launches, will ban female, gay bishops" retrieved 2/11/10 from www.usatoday.com.

${ }^{11}$ Carnegie Endowment for International Peace (2003, October 29), "The Chinese Communist Party's leadership and judicial independence", retrieved 2/11/10 from www.carnegieendowment.org/events/index.cfm? fa=eventDetail\&id=650.

${ }^{12}$ From CIA (2010) The Cuban "government continues to balance the need for economic loosening against a desire for firm political control ... The average Cuban's standard of living remains at a lower level than before the downturn of the 1990s, which was caused by the loss of Soviet aid and domestic inefficiencies." Retrieved 2/11/10 from www.cia.gov.

${ }^{13}$ CIA (2010), the Islamic Iran Participation Front "has repeatedly complained that the overwhelming majority of its candidates have been unfairly disqualified from the 2008 elections." Retrieved 2/11/10 from www.cia.gov.

${ }^{14}$ Most autocracies and organizations attempt to control information about it or issued from it; e.g., unprotected by tenure (CBS News, 2/11/10), the Louisiana State University scientist, van Heerden (he was the deputy Director of LSU's Hurricane Center and its Center for the Study of Public Health Impacts of Hurricanes, author of "The storm: What went wrong and why during Hurricane Katrina", sued after being fired by LSU for his criticism of the Army Corps of Engineers' design of levees that failed in New Orleans from Hurricane Katrina. He claims his rights to free speech were violated by LSU, that his findings besmirched the Federal government, and that LSU holds significant Federal grants. LSU Chancellor M. Martin countered that LSU

"wholeheartedly supports its faculty and values their research, teaching and scholarly publishing". In contrast, no one was fired or demoted by the Army Corps for the failure of the levees. Retrieved 2/11/10 from wap.cbsnews.com.

${ }^{15}$ Wall Street Journal (2/11/10), "Tensions flare in Tehran as Government supporters, opposition gather": with internet and cell phone texting disrupted, "opposition supporters have used their web sites to report news ... on social networking sites ... to bypass a ban on reporting anti-government demonstrations." If the government cannot keep the demonstrators under control, it risks appearing to be impotent.

${ }^{16}$ New York Times (2/11/10) "Europe promises 'coordinated action' to help Greece", retrieved 2/11/10 from nytimes.com.
} 


\section{SUMMARY}

Traditional social theory is at an impasse. We have proposed a fundamental theory of social physics centered around field and laboratory evidence based on bistable social interactions to generate and consume information. Our new theory is based on Bohr's [18] application of quantum measurement to 1 in social systems to explain multiple interpretations, Adelson's [19] view of illusions in the construction of reality, and the prevalence of Nash equilibria in democracies, but not autocracies. A Nash equilibrium is a bistable phenomenon that produces Social-Psychological Harmonic Oscillators to process information in multiple interpretations among observers sufficiently free to self-organize and decide on the best interpretation. In contrast, autocracies survive by destroying, suppressing or controlling Nash equilibria. Interestingly, contemporary social scientists often provide advice to end the existence of Nash equilibria [7].

Our theory is difficult for both scientists and the average person to understand because situational awareness for organisms, machines and robots is classical. Even for the oppositely directed experts who drive a Nash equilibrium, self-interests make them too partisan to fully grasp conjugate reality; in contrast, neutrals as novices are unable to retain their transient capture of reality (interviews of jury members, as entertaining as they may be, are irrelevant; in [40]). What is left is the tool employed daily by ordinary humans to study opponents by either attacking or watching attacks (e.g., price wars, courtroom challenges, scientific debates). As scientists, we need a theory to formalize and improve this process; to extend it to organizations and systems of humans, machines, and artificial agents; and to formally study dark social systems. Agent reports cannot ever recover reality, but they may confirm predictions. We know that applying 1 to agent-based systems is going to be difficult [41]. That is why we developed social physics, beginning with the conservation of information, to control mixed organizations and systems of humans, machines, and robots.

\section{REFERENCES}

1. NRC (2009), Applications of Social Network Analysis for building community disaster resilience, Magsino, S.L. Rapporteur, NRC for DHS Workshop, Feb 11-12, 2009, National Academy Press.

2. Carley, K.M. (2006), "Destabilization of covert networks," CMOT 12: 51-66.

3. Jasny, B. R., Zahn, L.M., \& Marshall, E. (2009). Science 325: 405.

4. Barabási, A.-L. (2009). "Scale-free networks: A decade and beyond." Science 325: 412-3.

5. Ahdieh, R.G. (2009), "Beyond individualism and economics," retrieved 12/5/09 from ssrn.com/abstract $=1518836$.

6. Luce, R. D., \& Raiffa, H. (1967). Games and decision. New York, Wiley.

7. Axelrod, R. (1984). The Evolution of Cooperation. New York, Basic.

8. Sanfey, A. G. (2007). Science 318: 598-602.

9. Schweitzer, F., Fagiolo, G., Sornette, D., Vega-Redondo, F., Vespignani, A., \& White, D.R. (2009). "Economic networks: The new challenges," Science 325: 422-5.

10. Nowak, M. A., \& Sigmund, K. (2004). Science 303: 793-799.

11. Bankes, S. C. (2002). "Perspective. Agent-based modeling." PNAS 99(3): 7199-7200.

12. Conzelmann, G., Boyd, R. Cirillo, V. Koritarov, C.M. Macal, M.J. North, P.R. Thimmapuram, and T. Veselka (2004). “Analyzing the Potential for Market Power Using an Agent-Based Modeling 
Approach: Results of a Detailed U.S. Power Market Simulation," International Conference on Computing, Communication and Control Technologies, Austin, TX.

13. Floreano, D. \& Keller, L. (2010), PLOS Biology, 8(1): 1-8.

14. Lawless, W. F., Bergman, M., Louçã, J., Kriegel, N.N. \& Feltovich, N. (2007). CMOT 13: 241281.

15. Lawless, W. F., Sofge, D.A., \& Goranson, H.T. (2009), "Conservations of Information: A New Approach to Organizing Human-Machine-Robotic Agents Under Uncertainty," Quantum Interaction. Third International Symposium, QI-2009. P. Bruza, Sofge, D.A., Lawless, W.F., Van Rijsbergen, K., \& Klusch, M. (Eds.), Springer.

16. Lindstädt, H. \& Müller, J. (2010, January), Making game theory work for managers, McKinsey Quarterly, published by McKinsey \& Company.

17. Parsons, T., Bales, R., \& Shils, E.A. (1953), "Working papers in the theory of action," Chapter 5, pp. 163-269, Free Press.

18. Bohr, N. (1955). The unity of knowledge. L. Leary. New York, Doubleday: 44-62.

19. Adelson, E. H. (2000). The New Cognitive Sciences, 2nd Ed. M. Gazzaniga (Ed.), MIT Press.

20. Zeilinger, A. (1999). Reviews of Modern Physics 71: S288.

21. Lawless, W. F., Rifkin, S., Sofge, D.A., Hobbs, S.H., Angjellari-Dajci.F., Chaudron, L. \& Wood, J. (2010, forthcoming). "Conservation of Information: Reverse engineering dark social systems," Structure and Dynamics: eJournal of Anthropological and Related Sciences.

22. Dietz, T., Ostrom, E., \& Stern, P.C. (2003). Science 3021907.

23. Coleman, J. J. (2003). "Campaign financing." CATO, www.cato.org/pubs/briefs/bp-084es.html.

24. Freer, R. D., \& Perdue, W.C. (1996). Civil procedure. Cincinatti, Anderson.

25. Lawless, W. F., Whitton, J., \& Poppeliers, C. (2008). ASCE Practice Periodical of Hazardous, Toxic, and Radioactive Waste Management 12(2): 70-78.

26. Bongard, J., Zykov, V., \& Lipson, H. (2006). Science 314: 1118-1121.

27. Kirk, R. (2003). "Massacres, drugs, and America's war in Columbia, Public Affairs," 2003.

28. Hayek, F. A. (1944/1994). The road to serfdom. UK/Chicago, Routledge Press.

29. Lawless, W. F., Castelao, T., and Ballas, J.A. (2000). IEEE Systems Man, \& Cybernetics 30(1): 119-126.

30. Simon, H. A. (1992). Psychological Science 3: 150-161.

31. Shafir, E., \& LeBoeuf, R.A. (2002). "Rationality," Annual Rev Psychology 53: 491-517.

32. Baumeister, R. F., Campbell, J.D., Krueger, J.I., \& Vohs, K.D. (2005, January). "Exploding The Self-Esteem Myth," Scientific American.

33. Bloom, N., Dorgan, S., Dowdy, J., \& Van Reenen, J. (2007). Qrtrly J Econ 122(4): 1351-1408.

34. Kelley, H. H. (1992). "Lewin, situations, and interdependence." J. Social Issues 47: 211-233.

35. Lawless, W.F., Whitton, J., A M., Dajci, Fjorentina, \& Poppeliers, C. (2010; under review), ASCE Practice Periodical of Hazardous, Toxic, and Radioactive Waste Management

36. May, R. M. (1973/2001). Stability and complexity in model ecosystems. Princeton University Press.

37. Foucoult, M. (1975 (Tr. 1977)). "Discipline and punish,” A. Sheridan, Tr., Paris, FR, Gallimard.

38. Costello, J., Director of Center for behavioral Epidemiology, Duke University (2009, July 7). Letter to Daniel Pine, DSM-V Work Group

39. Satel, S. (2010, Feb 20), "Prescriptions for psychiatric troubles," Wall Street J, p. W-13.

40. Polanyi, M. (1974). Personal knowledge. Chicago, University of Chicago Press.

41. Jamshidi, M. (2010, to appear). "Control of system of systems," Intelligent Control Systems. T. Nanayakkara, Sahin, F., \& Jamshidi, M. (Eds.). 2(8). Taylor \& Francis Publishers. 